\title{
Integrated Reporting and Sustainability: A Note on Perceptions of the Accounting Profession
}

\author{
Carol A Tilt ${ }^{\mathrm{a}}$; Maria Xydias-Lobo ${ }^{\mathrm{b}}$; Flavia Rodricks ${ }^{\mathrm{b}}$; Giao Reynolds ${ }^{\mathrm{c}}$ \\ ${ }^{a}$ University of South Australia, Australia \\ ${ }^{\mathrm{b}}$ Flinders University, Australia \\ ${ }^{\mathrm{c}}$ Torrens University Australia, Australia
}

\begin{abstract}
This study provides a preliminary investigation of perceptions of Integrated Reporting (IR) in Australia, as a developed country and leader in this area, and Hong Kong as an Asian country with an advanced capital market. The study compares the perceptions of IR readiness and acceptance in Australia and in Hong Kong through interviewing accounting professional associations and firms regarding their awareness of, and attitudes towards, IR. In particular, this study considers the perceptions of interviewees about the relationship between IR and Sustainability Reporting. Findings of the study suggest that the profession is taking a narrow, and explicitly financial, interpretation of the IIRC framework and does not consider it to be a replacement for other types of reporting.
\end{abstract}

Keywords: Australia; Hong Kong; Integrated Reporting; Sustainability Reporting

\section{Introduction}

While social and environmental reporting (or Triple Bottom Line Reporting) has been investigated for some years, Integrated Reporting (IR) is a new term (Watson, 2013) being used to promote reporting in a wider context than simply financial aspects of a firm's operations which add value. In Australia, a new guideline on a Business Model for Integrated Reporting (IR) was produced by the Technical Collaboration Group of the International Integrated Reporting Council (IIRC) in 2013, and this was followed by the release of a Consultation Draft by the IIRC for comment in the same year. Professional bodies, such as the Institute 
of Chartered Accountants in Australia, CPA Australia and the Hong Kong Institute of Certified Public Accountants, and 'Big 4' accounting firms, are all actively involved in the development and study of IR (IIRC, 2013a; 2013b).

The adoption of Social and Environmental reporting has been predominantly in Europe, the UK, the US and Australia/NZ, (de Villiers \& van Staden, 2012) with only recent research considering reporting in developing countries (Samkin, 2012). Only a small amount of research has considered it in Asia (although there has been a recent trend of considering environmental issues in China - e.g. Situ and Tilt (2012)). IR is being promoted globally, but its emphasis on 'value creation' (firm based) rather than on 'sustainability' (society based) means that it is likely to be adopted more readily in developed countries, or countries where the financial markets are more sophisticated (Sherman, 2012, Sridhar, 2012, Samkin, 2012).

This study investigates IR in Australia, as a developed country and leader in this area, and Hong Kong, as an Asian country that has an advanced capital market. While there are similarities in the two countries, differing perspectives may be offered in terms of Asian versus Western business culture, and this may impact on the perceptions of, and interest in, integrated reporting. Westwood and Posner (1997) found that managers in Hong Kong rated much lower than Australian managers in terms of the importance they place on the public and community value of business decisions. Hong Kong managers were also found to place much higher importance on government and institutions. Both issues may be relevant to perceptions of IR. As such, the study aims to:

- Review literature on IR to date, in both developed and developing countries

- Compare the perceptions of IR and IR readiness in Australia and in Hong Kong 


\section{Background}

The IIRC defines IR as:

"a process that results in communication, most visibly a periodic "integrated report", about value creation over time. An integrated report is a concise communication about how an organization's strategy, governance, performance and prospects lead to the creation of value over the short, medium and long term.... While the communications that result from Integrated Reporting (IR) will be of benefit to a range of stakeholders, they are principally aimed at providers of financial capital".

At the heart of IR is the growing realisation that a wide range of factors determine the value of an organisation - some of these are financial or tangible in nature and are easy to account for in financial statements (e.g. property, cash), while many are not (e.g. people, natural resources, intellectual capital, market and regulatory context, competition, energy security) (IIRC Website). Integrated Reporting demonstrates the broad and longer-term outcomes of the decisions organisations make, based on a wide range of factors, to generate value over time. It helps an organisation to communicate in a clear, well-articulated way how it is reporting on all the resources it utilises (including employees, supply chains and stakeholders) and the relationships between them, to create value in the short, medium and long term. Thus, helping investors to manage risks and allocate resources most efficiently.

Capital, in the IR context, includes Financial, Manufactured, Intellectual, Human, Social and relationship, and Natural capital. Thus, the overlap with traditional Triple Bottom Line (TBL) (Elkington, 1998) and Sustainability reporting is clear, but little has been done to date to investigate the relationship (de Boer, Hannington \& Jennings, 2013, Jensen \& Berg, 2012, Situ \& Tilt, 2012). This is important because IR has often been regarded as an appropriate mechanism for improved reporting on social, environmental and sustainability issues; and a framework within which reporting against the Sustainable Development Goals (SDGs) (UNDP, 2015) can be embedded (Adams, 2017). While there have been criticisms of the relevance of IR to sustainability (see below), the discussion has been predominantly academic.

IIRC is a global coalition of regulators, investors, companies, standard setters, the accounting profession and NGOs. Together, this coalition shares the view that communication about value creation should 
be the next step in the evolution of corporate reporting. IIRC is the global authority on Integrated Reporting (IR). Its mission is clear: to enable integrated reporting to be rooted into mainstream business practice in the public and private sectors. IIRC's long-term vision is 'a world in which integrated thinking is implanted within mainstream business practice in the public and private sectors, enhanced by Integrated Reporting (IR) as the corporate reporting norm' (IIRC Website).

IIRC provides leadership and advocacy of IR, but to be successfully adopted at a broad level, there is an important role for the accounting profession itself, that is, professional accounting associations as well as the major public accounting firms, to provide thought leadership and support.

\section{The Development of Integrated Reporting}

Although South Africa's JSE stock exchange was the first in the world to make 'integrated reporting' compulsory, this new form of corporate disclosure is being rolled out across the globe. At the heart of integrated reporting is capital market efficiency - "bridging the gap between management's value creation story and investors' assessment of business value and stewardship" (KPMG, 2012, p.5), and its aim to support the providers of financial capital in their capital allocation decisions. Recent research has confirmed that capital providers are the primary audience (Lai, Gaia \& Stacchezzini, 2017).

IR has been described as a reporting platform that provides a holistic view of the firm's value creation story by bringing together material information about an organisation's business model, strategy, governance, performance and prospects over the short, medium and long term (KPMG, 2012; IIRC, 2012; 2013a). While its early use can be traced back as early as 2002 to Danish biotechnology company, Novozymes (Eccles \& Krzus, 2010), it was not well recognised until August 2010 with the official formation of the IIRC and the subsequent introduction of Integrated Reporting discussion paper in 2011, the prototype framework in 2012 and just recently the consultation draft in April 2013.

Between 16 April and 15 July 2013, IIRC held a successful three months of engagement on the Consultation Draft of the International Integrated Reporting Framework. IIRC analysed the submissions to shape the Framework. The Consultation Period was launched at events in 10 of the world's largest capital markets on 16 April 2013, and from then 
extensive consultation took place with organisations across the world. People from Asia, Australia, New Zealand, Europe, Africa, appraised and gave their opinion on the Consultation Draft.

The Draft International Integrated Reporting Framework issued by IIRC in April 2013 takes a broader view of the key resources on which value creation depends. It is claimed that 'by describing, and measuring where it is practicable, the material components of value creation and, importantly, the relationships between them, integrated reporting results in a broader explanation of performance and outcomes than traditional reporting' (IIRC, 2012, p.51). In contrast to the traditional view of the four factors of production (land, labour, capital and organisation), the Framework defines the key organisational resources or value drivers in terms of six types of capitals: financial, manufactured, human, intellectual, natural and social and relationship capital. These capitals, as the storehouses of value, are inputs to a firm's business model. They are also enhanced, consumed, modified and/or destroyed as a result of the activities and outputs of the business model. What an integrated report does is that it combines the material information on the capitals that has traditionally been contained in separate reports into a single coherent whole (Hanks \& Gardiner, 2012). IIRC recommends an emphasis to be placed in integrated reports on making visible all the capitals, explaining how they affect the firm's ability to create and sustain value now and in the future. In doing so, a company would be required to communicate its ownership, control and influence on various forms of capital; temporal changes in the stock of each form of capital, interrelationships between forms of capital; and the effects of the capitals on the firm and the wider society (White, 2010). Such an approach to value reporting challenges organisations to demonstrate their accountability and stewardship of multiple forms of capital regardless of their ownership (Hanks \& Gardiner, 2012; IIRC, 2013a).

The release of the International Integrated Reporting Framework in December 2013 was an important milestone in the market-led development of corporate reporting. It follows a three-month global consultation led by IIRC earlier in the year, which evoked over 350 responses from every region in the world, the profuse majority of which expressed support for IR. Integrated Reports should include a forwardlooking perspective on the business corroborated by a look back on performance against strategies and strategic objectives. This marks a shift in focus from short term historical financial performance to providing an understanding of how management is driving the medium to 
long term business prospects. The cultural change required from report preparers is substantial (KPMG, 2012).

Integrated reports that contain generic descriptions without any supporting hard facts, or with hard facts relating to measures that are not critical to the future sustainability of the business, can be judged as 'window dressed' reports. For example, while reduced electricity consumption, carbon emissions and recycling may be an appropriate performance measure for a manufacturing company, those factors are not relevant to the ability of a financial institution to continue operating in the future and therefore need not be included in the integrated report but rather made available online as additional sustainability information. An integrated report should focus on only those factors that have the potential to influence the long-term sustainability of the company (Watson, 2013).

While many companies are disclosing information on risks, strategy, performance indicators and directors' remuneration, few companies are demonstrating the relationships between those items. If an organisation:

- consults a wide group of stakeholders to determine its key risks

- selects appropriate risks to inform its strategy

- chooses performance indicators that measure success in achieving that strategy, and

- rewards directors on those successes

then reporting on this process in an integrated report should be logical and appropriate (Watson, 2013).

The IIRC pilot programme that ran to September 2014 comprised a network of participating organisations that are contributing to the development of the framework thereby allowing participants time to test the Framework during their reporting cycle following the release of the IR Framework. The Pilot Programme comprised (IIRC website):

- The Business Network with over 100 businesses across the globe from multinational corporations to public sector bodies

- The Investor Network with over 35 investor organisations

Since the pilot took place, interest in IR has been developing, with the number of companies labelling their reports specifically as 'integrated' reports "growing slowly but steadily" (KPMG, 2017, p.24). In particular, 
places with the most significant increases include some lesser developed countries - four countries were noted in the most recent KPMG CSR reporting survey: Japan (+21 percentage points), Brazil and Mexico (both +16 percentage points) and Spain (+9 percentage points)" (p.24).

\section{The link between Integrated Reporting and Sustainability Reporting}

While research indicates a growing incidence of social and environmental and sustainability reporting world-wide, critiques of such reports have indicated that the growth in quantity of non-financial reporting does not correlate with high standards of quality in the information provided to stakeholders. Substantial literature has developed emphasising the inadequacies of most existing non-financial reporting and suggesting that such reporting has largely failed in its purpose of providing useful information to stakeholders that would drive improved corporate social and environmental behaviour (See for example, Barone, Ranamagar \& Solomon, 2013; Milne, Tregidga \& Walton, 2009; Wild, 2008; Cooper \& Owen, 2007; Gray \& Milne, 2002; Bebbington \& Gray, 2001).

These critiques assert that current sustainability reporting and other corporate responsibility, environmental and social reports are largely deficient in qualitative aspects of completeness, accuracy, transparency and relevance, and offer several reasons for the inadequacy of current sustainability reporting. These include the fact that such reporting is mostly voluntary, non-assured and lacks internationally imposed common guidelines or mandatory standards (Marx \& van Dyk, 2011). In the context of a lack of regulation, there is strong motivation for firms to utilise such reporting for legitimising strategies and reputation management (See for example, Barone et al. 2013; Milne et al., 2009; Gray \& Milne, 2002). In addition, reported social and environmental information is frequently provided in discrete sections within existing annual reports, in separate standalone reports, or as supplements to financial information. This non- integrated, 'silo' treatment of nonfinancial information fails to provide stakeholders with necessary links and connections to effectively evaluate business performance, strategy and future value creation (Hohnen, 2012).

As such, commentators have expounded the potential benefits of IR for firms (Lotter, 2013; Watson, 2013). Black Sun (2012) asserts that it 
leads to improved internal processes, provides opportunities for integrated thinking and helps to identify ways of creating value for stakeholders. Similarly, James (2013, p.27) concludes that "small and midsize companies and their stakeholders may benefit significantly by proactively adopting an integrated reporting approach".

Empirical research on Integrated Reports is still in its infancy due to the recentness of its introduction, but a number of studies have been conducted on the reports by participants in the integrated reporting pilot programme. Tweedie and Martinov-Bennie (2015, p.57) conclude that IR might improve sustainability outcomes and the capacity of "nonfinancial stakeholders to informally advance sustainability goals". However, several barriers have been identified, including defining the concept and terms such as 'integrated thinking' and 'value creation' (Dumay et al., 2017).

Further, Wild and van Staden (2013) find that the majority of companies in the pilot programme database operate in the financial services industry and therefore are not dominated by industries with high social and environmental impacts. This is different from observations in the literature on social environmental and reporting where companies with a high impact on the physical environment tend to report more. They also note that large accounting firms appear to have a significant influence over the auditing and assurance of the integrated reports (Wild \& van Staden, 2013).

This study provides some indication of the attitudes and opinions of both accounting firms and professional bodies to further explore the level of engagement with IR, the preparedness of firms for continued IR reporting, and the level of support being given to firms to adopt IR practice.

\section{Criticisms of Integrated Reporting}

Although reporting against indicators in the Global Reporting Initiative (GRI) is becoming a widespread form of sustainability reporting, its adoption is voluntary and the level of GRI implementation varies. In the context of a lack of regulation, there is strong motivation for firms to utilise such reporting for legitimising strategies and reputation management (See for example, Barone et al., 2013; Milne et al., 2009; Gray \& Milne, 2002). IR has been considered as having the potential to overcome these deficiencies, but recent criticisms on IR 
suggest this is unlikely to be the case as the sustainability aspect of IR has been diluted (Flower, 2015).

Wild and van Staden (2013) note that the majority of the companies in the IIRC pilot programme database operate in the financial services industry and therefore it is not dominated by industries with high social and environmental impacts. They also note that the large accounting firms appear to have a significant influence over the auditing and assurance of integrated reports (Wild \& van Staden, 2013).

At an internal level, McNally, Cerbone and Maroun (2017) discuss the difficulties managers face in terms of IR and existing accounting systems. They note that management systems are developing to facilitate the IR process, but data are often compiled manually on an ad hoc basis, which may undermine accuracy and reliability. Rather than engaging in integrated thinking, reports are compliance based and therefore has not led to changes in managers' mind-sets (Higgins, Stubbs \& Love, 2014; Stubbs \& Higgins, 2014) and any change that does occur appears to be incremental (Guthrie, Manes-Rossi \& Orelli, 2017). A further barrier to its adoption is that the content of IRs is 'difficult' in terms of readability (Du Toit, 2017).

Finally, there are a number of aspects of IR that have been identified as lacking in research. de Villiers, Hsiao and Maroun (2017), in their conceptual model of IR, identify stakeholder engagement, assurance and management control systems as three of these areas. While management accounting and control processes have been long embedded into sustainability accounting (life cycle costing, EMA, etc.), there is little understanding of how they relate to IR and appears to be left out of the 'integration' of relevant issues. This may be due to a perception that IR is part of financial accounting (reporting) rather than management accounting but the links are important. As de Villiers et al. (2017, p.452) note, for example:

"...integrated thinking may lead to stakeholder engagement, which may influence the management control systems chosen to support the integrated report that is published, which may in turn lead to assurance of the integrated report." 


\section{Research Method}

A triangulated two-phased approach was used for this study, albeit one which provides preliminary evidence of perceptions of, and readiness for, IR in the two countries examined. First, the literature and IIRC documents were reviewed to develop an understanding of the history of the development of IR which informed the interview questions used for the second phase. This resulted in the inclusion of questions grouped into three themes: awareness of, and attitudes towards, IR; current experiences; preparedness for IR, including resources available. The main issues raised under each theme are summarised in Table 1.

Table 1. Interview Themes

Interview Theme

Awareness and attitudes (including perceived links to sustainability reporting)

Experience (including barriers to adopting IR)

Preparedness (including resources available)

\section{Issues Raised in the literature}

What IR is, compared to current reporting (financial and sustainably)

Only conducted in limited industries; managers mindset not 'integrated thinking'; difficulty in reading IRs

Internal systems not set up to conduct IR systematically

Second, interviews were conducted with people in charge of IR for each major professional accounting body operating in Australia and Hong Kong and the IR managers of three 'Big 4' accounting firms (names are not identified for confidentiality reasons). This resulted in a sample of 5 interviewees. While provides a limited sample, and a limitation of the study, IR at the time of the research was in the early stages of development, with few firms choosing to produce an integrated report.

However, understanding attitudes towards IR are important as research has indicated that existing culture and attitudes in organisations will impact on its eventual take-up and acceptance (Dumay \& Dai, 2017). Thus, initial interviews were conducted with professional bodies to gain a preliminary understanding of the perceptions of IR within the profession. These were followed by interviews with two accounting firms (one in 
Australia and one in Hong Kong). Some differences were identified between Hong Kong and Australian attitudes, and these first four interviews were therefore followed up with another interview with a second accounting firm in Hong Kong to gain a deeper understanding of perceptions in that region, especially given that there is no prior research on IR in Hong Kong.

Semi-structured interviews were used to ensure comparability but also allow participants to express their views and attitudes towards IR freely. Interviews took place during 2014 and ranged from 25 to 45 minutes each. All interviews were audio-recorded and professionally transcribed for analysis.

\section{Findings}

In Australia, the interviewees from both the professional body and the Big 4 accounting firm strongly supported the introduction of IR and championed its use. They clearly consider, however, IR and Sustainability/Social and Environmental reporting to be distinct things. They affirmed their perception of IR as being about financial viability, and stakeholders of IR being financial stakeholders, or investors, one big 4 respondent noting that "The primary audience of an integrated report under the IRC framework is financial investors", even making it clear that until investors require it, there will be little demand for IR: "There's not a huge chorus out there saying, 'give me integrated reports' because the investors aren't saying we want them yet".

The interviewee from a professional body made similar comments, and cited materiality as the only factor that may link IR with sustainability. Specifically:

"It's actually not about sustainability. ... a lot of the members who were interested in sustainability saw it as all about sustainability. ...when ...talking about what creates and drives value in your company, sustainability actually might be very immaterial to your business, so it's not a reason to do it or not do it. So, if issues around natural capital and some of the issues around sustainability are material, then certainly there's that link, but it's not about sustainability." (Professional Body)

Interestingly, although IR is touted as a comprehensive form of reporting, the notion that IR could replace other forms of reporting, 
including sustainability reporting, was not supported, all respondents expressing the view that there will always be a place for special purpose reports, such as sustainability reports, for specific stakeholders. In a recent study by McNally et al. (2017, p. 481) it was noted that the format of IR "limits the development of management control systems and a supporting accounting infrastructure" also noting that, in South Africa:

“...integrated reporting was not seen as an opportunity for reevaluating underlying control and performance measurement systems or improving the communication of sustainability initiatives to stakeholders." (p. 489)

In sum, Australian interviewees noted that interest in IR was still emerging, but may have waned recently, but all saw themselves as having a strong role in promotion and education around what IR can do for firms and suggested the concept will evolve as this happens.

In Hong Kong, there was also clear support for IR evident and that professional bodies should and do take an interest in new developments. The interviewee from the professional body did note some resistance, and there was a strong sense of a 'wait and see' attitude with some uncertainty about its future, stating "I don't know, I really don't know (how it will develop)". There was a concern that although IR has some "very enthusiastic followers" there is currently low interest on the part of their members. Thus, one difference between the two groups was that the Australian respondents appeared more confident that IR would continue to develop and that both the professional bodies and large firms would be instrumental in leading the process. This most likely reflects that 'better reporting' has been on the agenda of the profession in Australia for some time, as noted by one interviewee (Big 4 Firm).

Hong Kong respondents did, however, seem to be more familiar with the IIRC than the Australian respondents, and noted they had been to workshops and events with Paul Druckman, the then Head of the IIRC. Similar to Australian respondents, they also saw IR as focused on investors, but there seemed to be more openness to a stronger link with CSR and sustainability, suggesting the focus is "the group who are interested in Corporate Reporting" (Professional Body) rather than general shareholders who are yet to indicate an interest in this type of information. Similarly, Hong Kong respondents spoke much more about stakeholders and communicating with them, stating that there is "a genuine move from the Big Firms in Hong Kong towards more stakeholder engagement" (Big 4). Thus, a second difference between the 
two countries appears to be that Hong Kong firms are more open to IR being about stakeholders beyond just investors. This finding contradicts that of Westwood and Posner (1997) who found little interest in the community in Hong Kong and more interest in institutions. An explanation may be that Hong Kong was found to have stronger links to the IIRC (treated with greater respect as a global institution) and the then Head has been quoted as suggesting that IR will "help bring sustainability reporting into the mainstream" (Adams, 2013). It may also reflect different cultural values; as noted earlier, Hong Kong has a developed capital market, but also has Chinese cultural traditions, including a more collectivist attitude (Hofstede Insights, n.d.).

Finally, there appeared to be greater awareness of IR in Hong Kong than in Australia. This may be related to the strong link to the IIRC and the tendency to regard institutions highly in Hong Kong. This level of 'power distance' (Hofstede, 1980) means it is more likely that the profession will see IR as a future requirement, rather than a suggestion, which is how some firms in Australia appear to perceive it. One respondents from Australia noted that some companies in Australia had little interest in knowing about IR at this stage as they had enough reporting requirements to deal with, without any additional ones (Professional Body).

A summary of the major themes emerging from the interviews is provided in Table 2, with differences highlighted in italics. Table 2 indicates that there are a number of similarities between the two countries, which is to be expected given the emerging nature of IR in both contexts. However, significant differences do appear as noted above, and the implications for this are discussed in the final section of the paper. 
Table 2. Major Themes

Australia

IR is important and has value to the firm

IR is not about Sustainability and there will always be separate sustainability reports

Awareness varies among accounting firms

Currently immature

Interest had died down recently

Criticism re investor focus should not be 'criticism' as IR was designed this way
Hong Kong

IR is important and has benefits to the firm and the community

IR is not about sustainability per se, but sustainability is an important element of integration

Awareness of IR and IIRC by the profession is high

Currently in its infancy but has promise for the future

Interest and awareness by accountants is low

Criticism re investor focus is unfair

Dominated by Big 4

\section{Conclusion}

While all respondents in this study clearly see IR as investor focused, those who appeared to have worked more closely with IIRC had a somewhat broader view of what IR can and should be. Interestingly, this was more noticeable in Hong Kong where respondents emphasised the notions of 'interconnectedness', integrated thinking' and 'stakeholder engagement'. This may reflect that the professions in more developed economies may depend less on guidance from IIRC and are confident enough to develop their own versions of what they consider IR should be. This has implications for the future of IR in developed economies and the importance of garnering support from powerful interest groups, such as the Big 4 accounting firms. However, more research is needed to ascertain whether this is the case.

Further, if IR is to maintain a link with broader notions of sustainability that are implied by an integrated thinking approach, the challenge will be for IIRC and its Board to provide thought leadership in this regard. Clearly this has been easier to do in Hong Kong where there 
are natural tendencies to allow global leadership, rather than natural resistance to change as seen in Australia.

There is also a need to examine in more detail, the internal mechanisms for how IR becomes embedded in organisations as most of the research to date has indicated some confusion and hesitation as to where it fits into the reporting landscape (Dumay et al., 2017). In a study on IR in Italy, Guthrie et al. (2017, p. 566) noted that "management accounting techniques played a pivotal role in the links between financial and non-financial data" in their case organisations. Thus, management accounting can clearly play a key role in promoting sustainability, and so further work on how internal mechanisms can promote integrated thinking, especially in terms of consideration of the trade-offs between the six capitals, is warranted.

It is important to note that the findings of this study are based on a small sample and therefore represent only preliminary information. There has been some additional take-up of IR in the years since this study therefore much more research is needed to compare these findings with more recent attitudes. Other areas for future research include how IR relates to other types of reporting, how integrated thinking is perceived by companies, and how stakeholders influence the perceptions of companies and the profession. 


\section{References}

Adams, C., (2013), "Integrated Reporting - What It is - And is Not: An Interview with Paul Druckman", Available online at: https://drcaroladams.net/integrated-reporting-what-it-is-and-is-not-aninterview-with-paul-druckman/ [Accessed 17 September 2018]. Adams, C., (2017), "The Sustainable Development Goals, Integrated Thinking and The Integrated Report: Summary Report", Available online at: http://integratedreporting.org/wp-content/uploads/2017/09/SDGs-andthe-integrated-report_summary2.pdf [Accessed 17 September 2018].

Barone, E., Ranamagar, N. and Solomon, J., (2013), "A Habermasian Model of Stakeholder (Non)engagement and Corporate (Ir)responsibility Reporting”, Accounting Forum, Vol. 37 No. 3, pp. 163-171.

Bebbington, J. and Gray, R. H., (2001), "An Account of Sustainability: Failure, Success and a Reconceptualisation", Critical Perspectives on Accounting, Vol. 12 No. 5, pp. 557-587.

Black Sun, (2012), "Understanding Transformation: Building the Business Case for Integrated Reporting", Available online at: http://integratedreporting.org/wp-content/uploads/2012/11/BUILDING-

THE-BUSINESS-CASE-FOR-INTEGRATED-REPORTING.pdf

[Accessed 17 September 2018].

Cooper, S. and Owen, D., (2011), "Corporate Social Reporting and Stakeholder Accountability: The Missing Link", Accounting, Organizations and Society, Vol. 32 No. 7-8, pp. 649-667.

de Boer, Y., Hannington, A. and Jennings, C., (2013), "Integrated Reporting Will Only Become Meaningful When Companies Begin Strategising for Future Value", Accountancy SA, Vol. 20 No. 1, p. 34.

de Villiers, C. and van Staden, C., (2012), "New Zealand Shareholder Attitudes towards Corporate Environmental Disclosure", Pacific Accounting Review, Vol. 24 No.2, pp. 186-210.

de Villiers, C., Hsiao, P.-C. K. and Maroun, W., (2017), "Developing a Conceptual Model of Influences around Integrated Reporting, New Insights and Directions for Future Research", Meditari Accountancy Research, Vol. 25 No. 4, pp. 450-460.

Dumay, J. Bernardi, C., Guthrie, J. and La Torre, M., (2017), "Barriers to Implementing the International Integrated Reporting Framework: A Contemporary Academic Perspective", Meditari Accountancy Research, Vol. 25 No.4, pp. 461-480. 
Dumay, J. and Dai, T., (2017), "Integrated Thinking as a Cultural Control?", Meditari Accountancy Research, Vol. 25 No. 4, pp. 574-604.

Eccles, R. G. and Krzus, M. P., (2010), One Report: Integrated Reporting for a Sustainable Strategy, John Wiley, Hoboken.

Elkington, J., (1998). Cannibals with Forks: The Triple Bottom Line of 21st Century Business, New Society Publishers, Gabriola Island.

Flower, J., (2015), "The International Integrated Reporting Council: A Story of Failure", Critical Perspectives on Accounting, Vol. 27, pp. 1-17.

Gray, R. and Milne, M., (2002), "Sustainability Reporting: Who's Kidding Whom?", Chartered Accountants Journal of New Zealand, Vol. 81 No. 6, pp. 66-70.

Guthrie, J., Manes-Rossi, F. and Orelli, R. L., (2017), "Integrated Reporting and Integrated Thinking in Italian Public Sector Organisations", Meditari Accountancy Research, Vol. 25 No. 4, pp. 553573.

Hanks, J. and Gardiner, L., (2012), Integrated Reporting: Lessons from the South African Experience, International Finance Corporation, Washington DC.

Higgins, C., Stubbs, W. and Love, T., (2014), "Walking the Talk(s): Organisational Narratives of Integrated Reporting", Accounting, Auditing and Accountability Journal, Vol. 27, No. 7, pp. 1090-1119.

Hofstede, G., (1980). Culture's Consequences: International Differences in Work-Related Values, Sage, Beverly Hills.

Hofstede Insights, n.d., "Country Comparison: Hong Kong”, Available online at: https://www.hofstede-insights.com/country-comparison/hongkong/ [Accessed 17 September 2018].

Hohnen, P., (2012), “The future of Sustainability Reporting”, Available online

https://www.chathamhouse.org/sites/files/chathamhouse/public/Research/ Energy\%2C\%20Environment\%20and\%20Development/0112pp_hohnen. pdf [Accessed 17 September 2018].

IIRC, (2012), "Integrated Reporting: Prototype of the International <IR> framework", Available online at: http://www.theiirc.org/wpcontent/uploads/2012/11/23.11.12-Prototype-Final.pdf [Accessed 17 September 2018]. 
IIRC, (2013a), "Consultation Draft of the International <IR > framework", Available online at: http://integratedreporting.org/wp-content/uploads/ 2013/03/Consultation-Draft-of-the-InternationalIRFramework.pdf

[Accessed 17 September 2018].

IIRC, (2013b), "Business Model Background Paper for <IR>”, Available online at:

https://integratedreporting.org/wpcontent/uploads/2013/03/Business_Model.pdf [Accessed 17 September 2018].

James, M. L., (2013), "Sustainability and Integrated Reporting: Opportunities and Strategies for Small and Midsize Companies", Entrepreneurial Executive, Vol. 18 No. 1, pp. 17-28.

Lai, A., Gaia, G. and Stacchezzini, R., (2017), "What Does Materiality Mean to Integrated Reporting Preparers? An Empirical Exploration", Meditari Accountancy Research, Vol. 25 No. 4, pp. 533-552.

KPMG, (2012), "Integrated Reporting: Performance Insight through Better Business Reporting (Issue 2)", Available online at: http://integratedreporting.org/wp-content/uploads/2012/06/KPMG-

Integrated-Reporting-Performance-Insight-Through-Better-BusinessReporting-Issue-2.pdf [Accessed 17 September 2018].

KPMG, (2017), "The Road Ahead: The KPMG Survey of Corporate Responsibility Reporting 2017", Available online at: https://assets.kpmg.com/content/dam/kpmg/xx/

pdf/2017/10/kpmg-survey-of-corporate-responsibility-reporting-2017.pdf [Accessed 17 September 2018].

Lusher, A. L., (2012), "What is the Accounting Profession's Role in Accountability of Economic, Social, and Environmental Issues?", International Journal of Business and Social Science, Vol. 3 No. 15, pp. 13-19.

Marx, B. and van Dyk, V., (2011), "Sustainability Reporting and Assurance: An Analysis of Assurance Practices in South Africa", Meditari Accountancy Research, Vol. 19 No. 1/2, pp. 39-55.

McNally, M., Cerbone, D. and Maroun, W., (2017), "Exploring the Challenges of Preparing an Integrated Report", Meditari Accountancy Research, Vol. 25 No. 4, pp. 481-504. 
Milne, M. J., Tregidga, H. and Walton, S., (2009), "Words Not Actions! The Ideological Role of Sustainable Development Reporting", Accounting, Auditing and Accountability Journal, Vol. 22 No. 8, pp. 1211-1257.

Samkin, G., (2012), "Changes in Sustainability Reporting by an African Defence Contractor: A Longitudinal Analysis”, Meditari Accountancy Research, Vol. 20 No. 2, pp. 134-166.

Sherman, W. R., (2012), "The Triple Bottom Line: The Reporting of "Doing Well" \& "Doing Good"”, Journal of Applied Business Research, Vol. 28 No. 4, pp. 673-681.

Situ, H. and Tilt, C. A., (2012), "Environmental Reporting in China: Volume, Determinants and the Role of the State", Journal of the Asia Pacific Centre for Environmental Accountability, Vol. 18 No. 4, pp. 251286.

Sridhar, K., (2012), "Corporate Conceptions of Triple Bottom Line Reporting: An Empirical Analysis into the Signs and Symbols Driving This Fashionable Framework", Social Responsibility Journal, Vol. 8 No. 3, pp. 312-326.

Stubbs, W. and Higgins, C., (2014), "Integrated Reporting and Internal Mechanisms of Change", Accounting Auditing and Accountability Journal, Vol. 27, No. 7, pp. 1068-1089.

Tweedie, D. and Martinov-Bennie, N., (2015), "Entitlements and Time: Integrated Reporting's Double-Edged Agenda", Social and Environmental Accountability Journal, Vol. 35 No. 1, pp. 49-61.

UNDP, (2015), "Sustainable Development Goals", Available online at: http://www.undp.org/content/undp/en/home/sustainable-developmentgoals.html [accessed 17 September 2018).

Watson, A., (2013), "Early Days Yet for Integrated Reporting, But Excellent Examples are Emerging", Accountancy SA, Vol. 20 No. 1, p. 33.

Westwood, R. I. and Posner, B. Z., (1997), "Managerial Values across Cultures: Australia, Hong Kong and the United States", Asia Pacific Journal of Management, Vol. 14 No. 1, pp. 31-66.

White, A. L., (2010), "The Five Capitals of Integrated Reporting: Toward a Holistic Architecture for Corporate Disclosure", in R. Eccles, B. Cheng, and D. Saltzman (ed.), The Landscape of Integrated Reporting: Reflections and Next Steps, Harvard Business School Press, Boston. 
Wild, S. and van Staden, C., (2013), "Integrated Reporting: Initial Analysis of Early Reporters - An Institutional Theory Approach", Proceedings of 7th Asian Pacific Interdisciplinary Research in Accounting (APIRA) Conference, Kobe, Japan.

Wild, S., (2008), "Sustainability Reporting in Fishing Industry Management - Regulation versus Voluntarism”, Australasian Accounting, Business and Finance Journal, Vol. 2 No. 3, pp. 57-70. 